\title{
Do nursing students know and practise the Universal Precautions to prevent transmission of infectious agents?
}

\author{
Authors: \\ Lindy S. van der Berg ${ }^{1}$ \\ Felicity M. Daniels ${ }^{1}$ \\ Affiliations: \\ ${ }^{1}$ School of Nursing, \\ University of the Western \\ Cape, South Africa \\ Correspondence to: \\ Lindy van der Berg \\ Email: \\ Ivanderberg@uwc.ac.za \\ Postal address: \\ Private Bag X17, Bellville \\ 7535 , South Africa \\ Dates: \\ Received: 09 Feb. 2012 \\ Accepted: 09 July 2013 \\ Published: 28 Aug. 2013 \\ How to cite this article: \\ Van der Berg, L.S. \& Daniels, \\ F.M., 2013, 'Do nursing \\ students know and practise \\ the Universal Precautions \\ to prevent transmission \\ of infectious agents?', \\ Curationis 36(1), Art. \#99, \\ 7 pages. http://dx.doi.org/ \\ 10.4102/curationis.v36i1.99

\section{Copyright:} \\ (C) 2013. The Authors. \\ Licensee: AOSIS \\ OpenJournals. This work \\ is licensed under the \\ Creative Commons \\ Attribution License.
}

Read online:

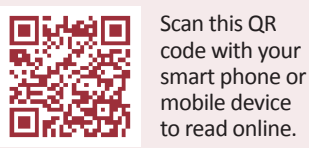

Background: Nursing students, like other healthcare students, are at high risk of occupational exposure to blood and bodily fluids. Studies have shown that use of the Universal Precautions (UPs) lowers this risk, but do students know and practise these precautions?

Objectives: This study investigated the knowledge and practice of undergraduate nursing students regarding the UPs, and whether there was a correlation between knowledge of the UPs and their practice.

Method: This was a descriptive quantitative study amongst undergraduate nursing students in years $2-4(n=253)$, who were selected by means of stratified random sampling. A questionnaire was administered to the participants by the researcher. The data collected were analysed through use of the Statistical Package for Social Sciences (SPSS 16.0) and content analysis.

Results: It was established that there was indeed a lack of knowledge regarding the UPs, and that the students' self-reported practice of the UPs was poor. There was no statistically significant correlation between knowledge and practice of the UPs.

Conclusion: More structured educational programmes are needed to improve both knowledge and practice of the UPs. These programmes should be offered across all nursing student study years as continuous professional development.

\section{Introduction \\ Problem statement}

\section{Key focus}

Healthcare workers, especially students in the healthcare profession, are at increased risk of occupational exposure to blood and bodily fluids. Proper knowledge and practice of the Universal Precautions (UPs) can significantly decrease the incidence of occupational exposure amongst students.

The UPs proposed by the Centers for Disease Control and Prevention (CDC) require that healthcare workers treat the blood and body fluids of all persons as potential sources of infection, irrespective of perceived risk or diagnosis (Siegel et al. 2007:93). The UPs are a set of guidelines that need to be followed in order to prevent transmission of blood-borne pathogens, for example the HIV, when a person is exposed to blood or other bodily fluids, or if there is a risk of potential exposure (Siegel et al. 2007:66).

\section{Background}

At the time of this study it seemed that the incidence of occupational exposure was on the rise amongst nursing students registered for the Baccalaureus Curationis degree at a higher education institution in the Western Cape. Although according to available records there seemed to be a decrease in reported cases from 2007 to 2008, with total numbers of reported incidents of six and four respectively over all 4 years of study (E. Kearns, pers. comm., 3 October 2008), there is still the possibility of under-reporting, as shown by various studies (Deisenhammer, Radon \& Reichert 2006; Patterson et al. 2003). Incidents involving students were mainly due to poor practice of the UPs, for example unsafe disposal of needles or not wearing protective clothing such as masks when delivering a baby in the labour wards.

In order to address the problem of occupational exposure, the cause needs to be identified. It was strongly suspected that there could be a link between a lack of knowledge of and inadequate practice of the UPs, and therefore a rise in occupational exposure. There may be other contributing factors involved, such as a lack of proper equipment, space and supplies as well as fatigue. 
Various studies have shown that healthcare students are at increased risk of occupational exposure to blood and bodily fluids (Hutin, Hauri \& Armstrong 2003; Patterson et al. 2003; Shiao et al. 2002). Proper knowledge and practice of the UPs can considerably decrease the incidence of occupational exposure amongst students (Motamed et al. 2006:654).

\section{Aim of the study}

The aim of the study was therefore to investigate the knowledge and practice of nursing students with regard to the UPs and whether there was any relationship between knowledge of and practice of the UPs.

\section{Research objectives}

The purpose of this research was to provide insight into whether nursing students are knowledgeable about and practise the UPs. The objectives were to investigate the knowledge and practice of undergraduate nursing students regarding the UPs, and to investigate the correlation between their knowledge and actual practice of the UPs.

\section{Contribution to the field}

Occupational exposure needs to be addressed, based on the potential risks associated with exposure. In order to address this problem, the cause needs to be identified. The following question may be asked: do nursing students know the UPs, and do they practise it consistently? Involvement of students in the study provided an opportunity for improvement in the curriculum based on their responses regarding their knowledge and practice. It will also result in better compliance from the students with regard to the UPs, with implementation of measures based on the study findings. The fact that they participated in the study hopefully evoked reflection on their own practice of the UPs.

\section{Literature review}

Although there is a wide range of studies and information with regard to the UPs, the literature review was limited to the most relevant aspects relating to this study. There are few studies regarding the UPs involving nursing students in the South African context, with a number of studies having been carried out abroad.

\section{Knowledge of the Universal Precautions}

Askarian and Malekmakan (2006) report on a survey regarding the frequency of needle-stick injuries and the knowledge, attitude and practices of medical, dental, nursing and midwifery students at university teaching hospitals in Shiraz, Iran. They found that $87.8 \%$ of the students received information with regard to the UPs, compared with the 98\% reported by Patterson et al. (2003:229). Askarian and Malekmakan (2006:230) argue the need for more structured education with regard to the UPs.

A study testing knowledge of the UPs shows that only $57.1 \%$ of nursing and midwifery students at Addis Ababa University Schools of Nursing and Midwifery in Ethiopia had 'sufficient knowledge' (Aga \& Mekonnon 2004:56), whilst a study by Motamed et al. (2006:653) reports a mean score of 78.1\% in respect of knowledge amongst medical students, indicating a 'low understanding' of the UPs. They also found that the UPs were understood not just poorly but also selectively. Chan et al. (2002:157) found the knowledge of nurses with regard to the UPs to be inadequate. In this study in Hong Kong the researchers tested the knowledge and practices of nurses with regard to the UPs and found their knowledge to be insufficient, with a mean total score of $66.1 \%$ (Chan et al. 2002:159).

The terms 'sufficient knowledge' and 'low understanding' were used by the original researchers in these studies. The authors do not compare their results with a specific amount of understanding, but compare it with the results of other studies. Aga and Mekonnon (2004), for example, do not state what they regard as 'sufficient knowledge' in their study, although they do attempt to describe (without much clarity) how they allocated the levels of knowledge. Despite this, the general observation from the literature is that knowledge of the UPs is low.

\section{Practice of the Universal Precautions}

Askarian and Malekmakan (2006) found that $96.2 \%$ of students reported wearing gloves during wound suturing. This is contrary to the findings of a study by Meaner et al. (2004), as cited in Askarian and Malekmakan (2006), regarding blood exposure accidents amongst medical students, who found that $50 \%$ of medical students did not use gloves. This evinces the fact that there is a variation in the practice of using gloves as a UP amongst medical students. It was also found that $88.4 \%$ of students recapped needles, whilst $64.4 \%$ of students did not follow the correct procedure for disposal of sharps (Askarian \& Malekmakan 2006:229). The percentage of students who did not routinely wear eye protection in operating and emergency rooms was $97.5 \%$, whilst $52.5 \%$ of dental students did wear eye protection routinely. The authors do not specify whether the use of eye protection was routinely necessary in the operating room and for which type of surgery. Wearing eye protection is not routine practice in every surgical procedure; it would therefore have been more relevant if they had stated the types of surgery where students were at risk of being exposed to bodily fluids and, ultimately, the risk of contracting a blood-borne pathogen.

According to a study by Motamed et al. (2006) conducted at two hospitals, almost all of the respondents (which included all medical staff and medical students) wore gloves, gowns and protective eyewear when exposed to blood products. A total of $19.2 \%$ of medical staff at hospital A and $60.3 \%$ at hospital B as well as $33.9 \%$ of medical students at both hospitals knew that it is not necessary to apply the UPs when exposed to sweat. Only $16.1 \%$ of medical staff at hospital A, $50.4 \%$ at hospital B and $25.2 \%$ of medical students at both hospitals knew that healthcare workers with non-intact skin should not be involved in direct patient care until the condition had resolved. This shows that they did not understand the risk of transmission of pathogens if these guidelines are not implemented. The practice of disposal of sharps was very good, with $94.8 \%, 99.3 \%$ and $100 \%$ 
respectively doing so correctly. This is in contradiction to the findings of the study by Askarian and Malekmakan (2006), who found that $11.6 \%$ of medical students reported that they 'rarely to never' recapped the needles, whilst $35.6 \%$ always discarded the needles in a sharps container.

\section{Relationship between knowledge of and practice of the Universal Precautions}

Only one of the studies reviewed looked at the correlation between knowledge and practice of the UPs (Motamed et al. 2006), finding a significant relationship between the two, with a Pearson correlation coefficient $(r)$ of 0.58 . As knowledge of the UPs increases, respondents become more compliant with the requirements of the UPs (Motamed et al. 2006:656).

From the literature it becomes evident that there are generally poor knowledge and practice of the UPs, although one study indicated that there is some relationship between the two. The findings of these studies form the basis for contextualising and understanding the study conducted to investigate the knowledge and practice of nursing students with regard to the UPs.

\section{Research method and design Design}

The study was quantitative using a correlational descriptive design (Macnee \& McCabe 2008:213). This research paradigm was used because the researcher wanted to determine descriptive statistics to explain the different variables, as well as inferential statistics to explore relationships amongst the variables.

\section{Materials}

A self-administered questionnaire used in a study carried out in Mazandaran Province (Iran), where the knowledge and practices of healthcare workers and medical students around the UPs were surveyed, was adapted for use in this study after permission was obtained from the lead researcher involved (Motamed et al. 2006).

In the adapted questionnaire Part 1 covered demographic data that focused on age, gender and year of study; Part 2 dealt with the knowledge of the participants with regard to the UPs; and Part 3 consisted of statements with regard to the participants' self-reported practices of UPs.

\section{Data collection method}

Data were collected over a period of 3 weeks at a higher education institution in the Western Cape. The questionnaire was self-administered by the students after an information session was conducted and consent was obtained.

\section{Population}

The target population was 722 undergraduate nursing students in the second to the fourth year of study, registered at one of the higher education institutions in the Western
Cape. The inclusion criterion was that students must have been exposed to clinical practice in real-life situations and not only in the skills laboratory or with simulated patients. First year students were therefore excluded since this group had very little real-life clinical exposure by the time data collection commenced. First year students only performed basic nursing care and not any invasive procedures.

Probability sampling was used. Due to unequal distribution in the three different years of study, proportional stratified random sampling with replacement was used (Leedy \& Ormrod 2005). A list of all the registered nursing students was obtained from Information and Communication Services of the university and the randomiser function in Microsoft Excel 2007 was used to select the sample. The sample was calculated according to guidelines from the Survey System website (Creative Research Systems 2008). A confidence level of 95\% and confidence interval of 4.97 were used, as calculated using the sample size calculator from the same website (Creative Research Systems 2008). Based on calculations, the sample size of this study was determined as 253 students, comprising $45.9 \%(n=116)$ second year students, $30.4 \%(n=77)$ third year students and $23.7 \%(n=60)$ fourth year students.

\section{Data analysis}

The Statistical Package for Social Sciences (SPSS) software version 16.0 was used to analyse the data. Frequency tables and percentage distributions were used to further describe the different variables. Statistical analysis (inferential statistics) was also done by means of SPSS. Non-parametric correlation tests were computed to determine whether there were any correlations, and if so, whether these were statistically significant. The probability of significance was set at 0.05 .

\section{Ethical considerations Potential benefits and hazards}

There were no known risks or potential benefits to the students who participated in the study. The students were, however, informed of the potential benefits to the nursing programme. Arrangements were made with the student counselling centre in the event that a student required support after completing the questionnaire.

\section{Recruitment procedures}

Higher Degrees Committee as well as the Senate Committee of the higher education institution provided ethical clearance and approved the proposal (study reference number 09/1/35). The researcher also obtained permission from the Dean of Research and the Head of the Nursing School. Participation in the study was voluntary, and all participants had the right to take part or not of their own free will.

\section{Informed consent}

On the day of administration of the questionnaire the researcher provided each participant with a written and verbal explanation of what the study entailed before obtaining their written informed consent. 


\section{Confidentiality}

Confidentiality was addressed on the day of administering the questionnaire and throughout the study. Since the researcher was conducting the research personally, the participants could be assured of the aforementioned both verbally as well as in writing on the information sheet handed to them. Participants' names were not recorded anywhere.

\section{Data protection}

All completed questionnaires were kept in a locked cupboard at the researcher's house and only the researcher and her supervisor had access to it. These questionnaires will be locked away for a minimum of 5 years before being destroyed.

\section{Trustworthiness}

\section{Reliability}

A pilot study was done in April 2009 to determine the reliability of the instrument. Cronbach's alpha was used to determine the reliability of the adapted questionnaire. The questionnaire was piloted and revised three times in order to get an acceptable Cronbach's alpha score of 0.71 .

\section{Validity}

The validity of the questionnaire could not be assumed just because it was an established instrument (McMillan \& Schumacher 1997:239). The consent form had to be handed back before a participant was handed a questionnaire. This was done to increase the internal validity of the study by controlling the intervening variable of leaking of the questionnaire. Those who did not consent to the study could therefore not leak the contents of the questionnaire to other students. Not all of the participants agreed, but all of those who agreed did sign the consent form.

The researcher administered the questionnaire to control intervening variables, such as students obtaining answers to questions beforehand. It was also done to address internal validity. The questionnaires were completed immediately and handed back to the researcher. The fact that students were not informed of their selection before the day of the data collection also contributed to controlling this intervening variable.

With regard to the issue of external validity, a proportional stratified random sampling design was used in order to generalise the findings of the target population. The question of the content validity of the questionnaire used in the study by Motamed et al. (2006) was addressed, by means of experts from the infection control committees of the two hospitals surveying the questionnaire (Motamed et al., 2006:655).

\section{Findings}

A total of 253 questionnaires were administered to students, of which 65 had missing data. All 253 questionnaires were used in order to generalise the findings to the population.

\section{Age, gender and year of study}

A total of 248 participants indicated their age, most (71.7\%) falling into the age group 19-29 years, as can be seen in Table 1 . The majority of the participants were female (83.0\%) and $17.0 \%$ were male. Most were second year students $(45.9 \%, n=116)$, followed by third year $(30.4 \%, n=77)$ and fourth year $(23.7 \%, n=60)$ students.

\section{Knowledge of the Universal Precautions}

A total of $77.9 \%(n=190)$ of the participants across the 3 years indicated that they had heard of the UPs. Questions 8-21 were in the form of a Lickert scale with the options 'true', 'false' and 'don't know'; the results are shown in Table 2. These questions tested the students' knowledge about the UPs.

TABLE 1: Age, gender and year of study (sample size $n=253$ ).

\begin{tabular}{llll}
\hline Variable & Categories & Frequency & $\mathbf{\%}$ \\
\hline Age (years) & $19-29$ & 178 & 71.7 \\
& $30-39$ & 52 & 21.0 \\
\multirow{2}{*}{ Gender } & $40-49$ & 18 & 7.3 \\
& Male & 43 & 17.0 \\
Year level of study & Female & 210 & 83.0 \\
& Second year & 116 & 45.9 \\
& Third year & 77 & 30.4 \\
& Fourth year & 60 & 23.7 \\
\hline
\end{tabular}

TABLE 2: Knowledge of the UPS.

\begin{tabular}{|c|c|c|c|}
\hline Statement & $\begin{array}{l}\text { Correct } \\
\text { answer }\end{array}$ & $\begin{array}{l}\text { Incorrect } \\
\text { answer }\end{array}$ & $\begin{array}{l}\text { Don't } \\
\text { know }\end{array}$ \\
\hline UPs are applied when caring for patients with HIV and HBV only. (F) & 62.2 & 21.7 & 16.1 \\
\hline UPs should be applied caring for all persons regardless of their infection status. (T) & 86.8 & 5.2 & 8.0 \\
\hline Used needles can be recapped after giving an injection. (F) & 88.0 & 10.8 & 1.2 \\
\hline Subcutaneous injuries to the healthcare worker during intravenous injections are the most common cause of occupational infections. (T) & 34.8 & 18.2 & 47.0 \\
\hline Universal precautions are not necessary in situations that might lead to contact with saliva. ( $T$ ) & 16.8 & 64.4 & 18.8 \\
\hline For decontamination of devices such as baumanometer (only contact with skin) washing with usual detergent is enough. (T) & 53.6 & 39.5 & 6.9 \\
\hline Blood spills should be cleaned up promptly with sodium hypochlorite. (T) & 59.0 & 14.6 & 26.4 \\
\hline Hands should always be washed after contact with a patient. (T) & 98.8 & 0.8 & 0.4 \\
\hline For contact with blood and bodily fluids during non-surgical patient care, a single pair of gloves generally provides adequate barrier protection. (T) & 63.6 & 32.4 & 4.0 \\
\hline $\begin{array}{l}\text { The cleaning and disinfection of all patient-care areas is important for frequently touched surfaces, especially those closest to the patient, that are most } \\
\text { likely to be contaminated (e.g. bed rails, bedside tables, commodes, doorknobs, sinks, surfaces and equipment in close proximity to the patient). (T) }\end{array}$ & 97.2 & 0.4 & 2.4 \\
\hline It is not necessary to wash hands after contact with a patient's intact skin (e.g. when taking the pulse or blood pressure or lifting a patient). (F) & 90.0 & 8.4 & 1.6 \\
\hline Gowns can be reused for repeated contacts with the same patient. (F) & 74.8 & 17.6 & 7.6 \\
\hline
\end{tabular}

$T$, true; $F$, false according to the researcher. 
As seen in Table 2, only $51.5 \%$ of participants knew that isolation is not necessary for all patients with blood-borne infections, and only $34.8 \%$ knew that subcutaneous injuries during intravenous injections are the most common cause of occupational infection amongst healthcare workers. Only $16.8 \%$ of participants knew that the UPs are not necessary in situations that might lead to contact with saliva, and $47.2 \%$ agreed that healthcare workers with non-intact skin should not be involved with direct patient care until the condition is resolved. Another unexpected discovery was that $88.0 \%$ of the participants knew that used needles cannot be recapped after giving an injection.

Each participant was allocated a total score for all of their correct answers to the 14 statements testing their knowledge, and then given a percentage reflecting their total score for knowledge, as shown in Table 3.

\section{Practice of the Universal Precautions}

Although there were only right or wrong options, a five point Lickert scale was used to obtain a more accurate understanding of the practices of participants regarding the UPs, as can be seen in Table 4. As done with knowledge, participants were allocated a total score for the correct answers and given a percentage for practice.

\section{Correlations}

A Spearman's Rank Order correlation was run to determine the relationship between knowledge of the UPs and their practice. There was a very weak, positive correlation between total score for knowledge and total score for practice of the UPs, which was not statistically significant $(\rho(253)=0.090$, $p=0.153$ ). The null hypothesis, that there is no significant relationship between total score for knowledge and total score for practice, cannot be rejected. There is not enough evidence to state that the alternative hypothesis, that there is a significant

TABLE 3: Total scores for knowledge and practice (\%).

\begin{tabular}{lllllll}
\hline Variable & Mean & Median & Mode & SD & Minimum & Maximum \\
\hline Knowledge & 65.0 & 64.3 & 71.4 & 13.0 & 0 & 92.9 \\
Practice & 63.0 & 66.7 & 66.7 & 14.0 & 0 & 91.7 \\
\hline
\end{tabular}

SD; standard deviation. relationship between total score for knowledge and total score for practice, is true at the $95 \%$ confidence interval.

\section{Discussion Outline of results}

The mean score for knowledge in this study was $65.0 \%$, which indicates that there was a low level of knowledge of the UPs. This score corresponds with the findings of a study by Chan et al. (2002). A score of $100 \%$ would be desirable, whilst a score above $80.0 \%$ would be acceptable for knowledge and practice of the UPs. Students need to have $100 \%$ knowledge in order to protect them adequately against occupational exposure. One cannot be expected to practise safely without $100 \%$ knowledge. The fact that accidents do happen even though all necessary precautions have been taken is acknowledged; however, research has shown that the incidence of occupational exposure can be decreased if there is sufficient knowledge of and compliance with the UPs. Knowledge of the UPs is crucial to all healthcare workers in order to adequately protect their health and that of their patients. Collective year level scores were not looked at, but individual student scores were assessed in order to make a judgement of what constitutes a good, acceptable or low (poor) level of knowledge and/or practice of the UPs.

Other studies with similar findings include those by Motamed et al. (2006) and Tavolacci et al. (2008). A literature review by Gammon and Gould (2005:529) of various studies carried out worldwide found that knowledge of the UPs is insufficient.

The mean score for practice of the UPs in this study was 63\%, which is low. This corresponds to a study by Sadoh et al. (2006), which found the practice of the UPs to be suboptimal.

The practice of wearing gloves when at risk of occupational exposure is acceptable, with $92.8 \%$ indicating that they always wear gloves when there is a risk of contamination with blood and bodily fluids. In terms of the safe disposal of used needles, $94.4 \%$ have good practices. The results for 'washing of hands after handling specimens' are good $\mathbf{( 9 2 . 1 \% )}$ compared with the results for 'washing of hands after removing gloves', which only $73.6 \%$ of participants said

\section{TABLE 4: Practice of the UPs (\%).}

\begin{tabular}{|c|c|c|c|c|c|}
\hline Statement & Always & Usually & Sometimes & Seldom & Never \\
\hline I assume that blood and all bodily fluids of patients are infectious. (A) & 63.5 & 13.1 & 21.8 & 0.8 & 0.8 \\
\hline I use protective equipment, for example mask, gown and eye wear, for a procedure depending on my observation of the patient. (N) & 36.3 & 21.1 & 31.0 & 7.2 & 4.4 \\
\hline I immediately dispose of a used needle in a sharps container. (A) & 94.4 & 3.6 & 1.6 & 0.0 & 0.4 \\
\hline I wear gloves when there is a risk of being contaminated with the blood or bodily fluids of a patient. (A) & 92.8 & 4.8 & 1.6 & 0.8 & 0.0 \\
\hline Washing with soap and water for 5 minutes is my first step after contact with infective material. (N) & 66.8 & 20.0 & 7.6 & 3.6 & 2.0 \\
\hline I apply the UPs in situations that might lead to contact with sweat. $(\mathrm{N})$ & 32.3 & 24.6 & 25.4 & 8.4 & 9.3 \\
\hline If I have a wound, I wear gloves before caring for patients. (A) & 88.1 & 7.5 & 3.2 & 0.8 & 0.4 \\
\hline I apply the UPs in situations that might lead to contact with vaginal discharge. (A) & 91.7 & 4.0 & 1.9 & 1.2 & 1.2 \\
\hline I wash my hands after handling a specimen, regardless of the diagnosis of the patient. (A) & 92.1 & 4.3 & 2.4 & 0.8 & 0.4 \\
\hline I cautiously avoid injury from used needles. (A) & 93.6 & 4.8 & 0.8 & 0.4 & 0.4 \\
\hline I wash my hands after removing gloves. (A) & 73.6 & 13.6 & 11.6 & 0.8 & 0.4 \\
\hline $\begin{array}{l}\text { I wear a gown during procedures and patient-care activities when contact of clothing/exposed skin with blood/bodily fluids, } \\
\text { secretions, and excretions is anticipated. (A) }\end{array}$ & 52.6 & 16.6 & 19.0 & 5.5 & 6.3 \\
\hline
\end{tabular}

A, always; $N$, never. 
they practised. These findings seem to correspond with those of Askarian and Malekmakan (2006), Motamed et al. (2006), Bamigboye and Adesanya (2006) and Sadoh et al. (2006).

Practices with regard to 'wearing protective equipment based on the observation of the patients' are extremely poor, with a total of $4.4 \%$ indicating that they never 'wear protective equipment based on observation of the patient alone'. One would expect that they would all have known never to wear protective equipment based on the observation of the patient alone. By observation alone one cannot determine whether the patient has an infection or not. Therefore healthcare workers can place themselves at risk if they do not regard all patients as being potentially infected, especially when there is a risk of being exposed to blood and bodily fluids.

One would also have expected that $100 \%$ of the participants would assume that the blood and bodily fluids of patients are infectious, instead of only $63.5 \%$. It could be that students are not cautious of the fact that blood or bodily fluids may be infectious.

The fact that only $52.6 \%$ of participants indicated that they wear gowns in situations where contact of clothing or exposed skin with blood or bodily fluids, secretions and excretions is anticipated may be attributed to the fact that gowns are not readily available in most facilities. However, this was not asked in the study. This should have been anticipated and the question rephrased to read 'If gowns were readily available ...'

Only $9.3 \%$ knew that it is not necessary to apply the UPs to situations where they come into contact with saliva. The Centers for Disease Control and Prevention guidelines state that it is not necessary to use the UPs in such situations (Siegel et al. 2007:143). This percentage is far lower than those found in a study by Motamed et al. (2006), namely 19.2\% at hospital A and $60.3 \%$ at hospital B.

In their global literature review Gammon and Gould (2005) also found compliance with the UPs to be low. Based on these findings, one can therefore safely deduce that knowledge and practice of the UPs amongst undergraduate nursing students at the higher education institution in this study is inadequate.

\section{Correlation between knowledge and practice}

There is no significant correlation between the total score for knowledge and the total score for practice in this study. This means that there is no significant relationship between knowledge and practice of the UPs. If there had been a statistically significant correlation between the two, the practice of the UPs would have increased as the level of knowledge increased. This is contrary to what Motamed et al. (2006) found in their study, but corresponds with the findings of Chan et al. (2002), who also found no significant correlation in their study.

As discussed earlier, there was a need to determine whether the students' knowledge of the UPs was poor and whether, as a consequence, their practice was poor, as a possible reason for the incidence of occupational exposure amongst students at the School of Nursing. However, based on the findings it can be deduced that in this particular study there is no relationship between the two variables.

\section{Practical implications}

Preliminary results were made available to all academics teaching UPs programmes and who incorporate the UPs in the modules they offer, so that they could incorporate remedial steps specifically for students who demonstrated a low level of or non-compliance with the UPs. This was also done so that academics could strengthen and reinforce the use of the UPs.

Not all intervening factors were taken into account, for example the work environment, availability of equipment and modelling of the wrong practices of staff. With regard to these intervening variables, it is therefore necessary to study the impact of the work environment and existing practices which students model in relation to the practice of the UPs. In terms of the programme at the School of Nursing, this means that the existing educational module with regard to the UPs is inadequate as far as the students' knowledge is concerned. The curriculum needs to include a more structured educational programme with regard to the UPs.

The findings relating to practice are based on the self-reporting of practice; the use of other methods, for example direct observation in the facilities, might yield different results. Future research should be considered in order to establish whether there are certain relationships between variables, for example gender or year level and practice of the UPs.

Increasing knowledge of the UPs amongst nursing students would not necessarily lead to an increase in the practice of the UPs. Intervention programmes therefore should not focus only on increasing the knowledge but also the practice of the UPs.

\section{Limitations of the study}

This study examined students' knowledge and self-reported practice of the UPs, and the correlation between the two variables. There are many other correlations that could be considered, for example between gender or year levels and knowledge or practice.

The impact of other intervening factors, for example work environment and practices of staff, were not investigated in this study and can therefore be a limitation of the study, since the knowledge and more specifically practice of the UPs may be influenced by these factors.

Although all possible controls were in place, the data collection procedure meant there was a possibility that the results would not be a true reflection of the population, if participants informed each other about the questions in the questionnaire before the questionnaires were administered 
to them. It was planned to overcome this by making sure that data collection was done over a short period, so that participants from other years of study were not advised of the content of the questionnaire. Unfortunately, due to problems beyond the control of the researcher, this could not be achieved, and it may therefore be viewed as a limitation.

\section{Recommendations}

Specific recommendations in terms of research and practice were made throughout the article, but the recommendation concerning education needs to be expanded upon. As mentioned, educational programmes regarding the UPs are needed or need to be intensified and better structured, as has also been suggested in various other studies (Bamigboye \& Adesanya 2006; Chan et al. 2002; Motamed et al. 2006; Ndikom \& Onibokun 2007). These educational programmes should not only focus on supplying students with knowledge of the UPs but should also focus on behaviour modification to improve the practice of the UPs.

These programmes should be offered across all years of study to continuously reinforce knowledge through practice, and should also be incorporated within the clinical teaching and facilitation of students in the clinical setting. More emphasis should be given to clinical teaching and learning with specific reference to strengthening critical thinking, for example through case studies and simulation in the practice of nursing. More stringent mechanisms should be built in throughout the teaching (e.g., reinforcement), learning (e.g., modelling) and assessment of clinical skills (e.g., inclusion of the UPs into evaluation tools) to emphasise those critical factors which will differentiate good from poor practice of the UPs when managing patients. It has been proven that reinforcement leads to behaviour modification (Keating 2010:53).

Further studies are also recommended with regard to the UPs, in order to gain more understanding. These studies should be done qualitatively rather than quantitatively, because they could then focus more on the perceptions of students.

\section{Conclusion}

It is evident that there are insufficient levels of knowledge and practice of the UPs amongst undergraduate nursing students at this higher education institution in the Western Cape. Students need educational programmes not only to equip them with sufficient knowledge of UPs, but also to bring about behaviour modification in order to improve their practice. This can be achieved with positive reinforcement for compliance with the UPs in the clinical field, both by the clinical supervisor and staff who interact with the students.

The benefit of this study is that just by participating in this study students were made aware of their own practices of the UPs. Benefits for healthcare organisations and policy makers are that they now know that there is indeed a lack of knowledge and practice of the UPs amongst nursing students - and that intervention is needed to improve these.

\section{Acknowledgements Competing interests}

The authors declare that they have no financial or personal relationship(s) which may have inappropriately influenced them in writing this article.

\section{Authors' contributions}

L.S.v.d.B. (University of the Western Cape) was the primary researcher, performed all of the data collection, prepared the samples and performed calculations. F.M.D. (University of the Western Cape) was the supervisor of the mini thesis and made conceptual contributions, whilst both L.S.v.d.B. and F.M.D. wrote the manuscript.

\section{References}

Aga, F. \& Mekonnon, H., 2004, 'Knowledge of universal precautions and fears of occupational exposure to HIV/AIDS among student nurses and midwives in Ethiopia', Africa Journal of Nursing and Midwifery 6(1), 56-60.

Askarian, M. \& Malekmakan, L., 2006, 'The prevalence of needle stick injuries in medical, dental, nursing and midwifery students at the university teaching hospitals of Shiraz, Iran', Indian Journal of Medical Sciences 60(6), 227-232. http://dx.doi. org/10.4103/0019-5359.25904, PMid:16790948

Bamigboye, A.P. \& Adesanya, A.T., 2006, 'Knowledge and practice of universal precautions among qualifying medical and nursing students: A case of Obafemi Awolowo University Teaching Hospitals Complex, ILE-IFE', Research Journal of Medicine and University Teaching Hospitals Compl
Medical Sciences 1(3), 112-116.

Chan, R., Molassiotis, A., Chan, E., Chan, V., Ho, B., Lai, C. et al., 2002, 'Nurses' knowledge of and compliance with universal precautions in an acute care hospital' International Journal of Nursing Studies 39(2), 157-163. http://dx.doi.org/10.1016/ S0020-7489(01)00021-9

Creative Research Systems, 2008, 'Sample Size Calculator', viewed 14 November 2008, from http://www.surveysystem.com/sscalc.htm\#two

Deisenhammer, S., Radon, K. \& Reichert, J., 2006, 'Needlestick injuries during medical training', Journal of Hospital Infection 63(3), 263-267. http://dx.doi.org/10.1016/j. jhin.2006.01.019, PMid:16650505

Gammon, J. \& Gould, D., 2005, 'Universal precautions. A review of knowledge, compliance and strategies to improve practice', Journal of Research in Nursing 10(5), 529-547. http://dx.doi.org/10.1177/136140960501000503

Hutin, Y., Hauri, A.M. \& Armstrong, G.L., 2003, 'Use of injections in healthcare settings worldwide, 2000: Literature review and regional estimates', British Medical Journal 327(7423), 1075. http://dx.doi.org/10.1136/bmj.327.7423.1075, PMid:14604927, PMCid:PMC261740

Keating, S.B., 2010, Curriculum development and evaluation in nursing, 2nd edn., p. 53, Springer, New York.

Leedy, P.D. \& Ormrod, J.E., 2005, Practical research: Planning and design, 8th edn., pp. 199-207, Pearson, Upper Saddle River.

Macnee, C.L. \& McCabe, S., 2008, Understanding nursing research: Reading and using research in evidence-based practice, 2nd edn., pp. 193-220, Lippincott Williams \& Wilkins, Philadelphia.

McMillan, J.H. \& Schumacher, S., 1997, 'Data collection techniques', in J.H. McMillan \& S. Schumacher (eds.), Research in education: A conceptual introduction, pp. 234-275, Longman, New York. PMid:9158091, PMCid:PMC1904647

Motamed, N., Babamahmoodi, F., Khalilian, A., Peykanheirati, M. \& Nozari, M., 2006 'Knowledge and practices of health care workers and medical students towards universal precautions in hospitals in Mazandaran Province', Eastern Mediterranean Health Journal 12(5), 653-661. PMid:17333806

Ndikom, C.M. \& Onibokun, A., 2007, 'Knowledge and behaviour of nurses/midwives in the prevention of vertical transmission of HIV in Owerri, Imo State, Nigeria: A cross-sectional study', BMC Nursing 6(9), viewed 3 August 2011, from http:// www.biomedcentral.com.ezproxy.uwc.ac.za/content/pdf/1472-6955-6-9.pdf

Patterson, J.M., Novak, C.B., Mackinnon, S.E. \& Ellis, R.A., 2003, 'Needlestick injuries among medical students', American Journal of Infection Control 31(4), 226-230. $\mathrm{http} / / / \mathrm{dx}$.doi.org/10.1067/mic.2003.44, PMid:12806360

Sadoh, W.E., Fawole, A.O., Sadoh, A.E., Oladimeji, A. \& Sotiloye, O.S., 2006, 'Practice of universal precautions among healthcare workers', Journal of the National Medical Association 98(5), 722-726. PMid:16749647, PMCid:PMC2569287

Shiao, J.S., Mclaws, M.L., Huang, K.Y. \& Guo, Y.L., 2002, 'Student nurses in Taiwan at high risk for needlestick injuries', Annals of Epidemiology 12(3), 197-201. http:// dx.doi.org/10.1016/S1047-2797(01)00303-9

Siegel, J.D., Rhinehart, E., Jackson, M., Chiarello, L. \& the Healthcare Infection Contro Practices Advisory Committee, 2007, Guideline for isolation precautions: Preventing transmission of infectious agents in healthcare settings, viewed 12 July 2012, from http://www.cdc.gov/ncidod/dhqp/pdf/isolation2007.pdf

Tavolacci, M.P., Ladner, J., Bailly, L., Merle, V., Pitrou, I. \& Czernichow, P., 2008, 'Prevention of nosocomial infection and standard precautions: Knowledge and source of 29(7), 642-647. http://dx.doi.org/10.1086/588683, PMid:18611166 